\title{
Crystal structures and other properties of ephedrone (methcathinone) hydrochloride, $\mathrm{N}$-acetylephedrine and $\mathrm{N}$-acetylephedrone
}

\author{
Piotr Kuś ${ }^{1} \mathbb{D} \cdot$ Hubert Hellwig ${ }^{1} \cdot$ Joachim Kusz $^{2} \cdot$ Maria Książek $^{2} \cdot$ Marcin Rojkiewicz $^{1} \cdot$ Aleksander Sochanik $^{3}$
}

Received: 2 May 2018 / Accepted: 25 July 2018 / Published online: 18 August 2018

(c) The Author(s) 2018

\begin{abstract}
Purpose Three compounds obtained from ephedrine were identified and characterized by various instrumental analytical methods. Ephedrone (methcathinone) hydrochloride and its fundamental derivatives $N$-acetylephedrine and $N$-acetylephedrone were analyzed as precursors of a cathinone derivative.

Methods The obtained samples were analyzed by gas chromatography coupled with mass spectrometry, nuclear magnetic resonance spectroscopy, infrared and Raman spectroscopy, and X-ray crystallography.

Results The three compounds were confirmed as: $N$-methyl-2-amino-1-phenylpropan-1-one (methcathinone) hydrochloride, $N$-acetyl- $N$-methyl-2-amino-1-phenylpropan-1-one (cathinone derivative), and $N$-acetyl- $N$-methyl-2-amino-1-phenylpropan1-ol (acetyl derivative of ephedrine).

Conclusions X-ray crystallography is especially useful for identifying the new designer drugs and their different precursor forms.
\end{abstract}

Keywords Methcathinone (ephedrone) · Ephedrine as synthesis precursor · X-ray crystallography · Infrared spectroscopy · Raman spectroscopy $\cdot$ NMR spectroscopy

\section{Introduction}

Ephedrone (1) is one of the oldest known synthetic cathinones [1-3]. Its production has been based on ephedrine [(IR,2S)-1-phenyl-1-hydroxy-2-( $N$-methylamino)propane], a substance occurring naturally in shrubs of the genus Ephedra, native to parts of Europe, Asia, and the Americas. The ephedrine molecule contains two chiral carbon atoms and can therefore occur as four chiral isomers: two erythro [L-(-)-ephedrine and D-(+)-ephedrine], and two threo

Electronic supplementary material The online version of this article (https://doi.org/10.1007/s11419-018-0436-7) contains supplementary material, which is available to authorized users.

Piotr Kuś

pkus@ich.us.edu.pl

1 Department of Chemistry, University of Silesia, 9 Szkolna Street, 40-006 Katowice, Poland

2 Institute of Physics, University of Silesia, 4 Uniwersytecka Street, 40-007 Katowice, Poland

3 Center for Translational Research and Molecular Biology of Cancer, Maria Skłodowska-Curie Memorial Cancer Centre and Institute of Oncology, 44-100 Gliwice, Poland isomers [(-)-pseudoephedrine and (+)-pseudoephedrine] (Fig. 1). Levorotatory ephedrine occurs naturally.

Ephedrine (in general) has been listed as a drug precursor in Regulation No. 273/2004 of the European Parliament and of the Council (Annex 1).

Numerous anti-inflammatory, antipyretic, and analgesic drugs available over the counter contain pseudoephedrine, from which ephedrone can be produced at home via oxidation of the partially separated component of the medication. Pseudoephedrine contained in pills is oxidized using potassium permanganate and an acetic acid milieu $[4,5]$ or, alternatively, using potassium dichromate in sulfuric acid [6]. Procedures of this type make it impossible to completely remove manganese or chromium ions from the mixture; therefore, compounds containing these elements can enter the human body. Literature data include reports linking the presence of manganese ions delivered in such a manner with Parkinson's disease, possibly as a causative factor [7, 8]. Organic synthetic procedures for obtaining ephedrone from ephedrine and its analogues have also been reported [9-11].

Data concerning the crystallographic structures of ephedrone derivatives have been reported for metaphedrone hydrochloride [12], 2-MMC and 4-CMC hydrochlorides 
Fig. 1 Structures of $N$-methyl2-amino-1-phenylpropan-1-one (ephedrone) hydrochloride (1); $N$-acetylephedrine (2), and $\mathrm{N}$-acetyl- $\mathrm{N}$-methyl-2-amino1-phenylpropan-1-one ( $N$-acetylephedrone) (3)<smiles>CNC(C)C(=O)c1ccccc1</smiles>

1<smiles>CC(=O)N(C)C(C)C(O)c1ccccc1</smiles>

2<smiles>CC(=O)N(C)C(C)C(=O)c1ccccc1</smiles>

3
[13], methylone, mephedrone, and 1-(3,4-dimethylphenyl)2-(methylamino)propan-1-one HCl [14]. For mephedrone derivatives, conditions have been specified (change of halide ion) that alter its physicochemical characteristics (phase transition temperatures and melting points) [15].

Despite no reported use of acetylated ephedrone derivative 3 as a designer drug, we determined the spectroscopic and crystallographic properties of this cathinone derivative, as well as those of its precursor, compound 2, which is an acetylated ephedrine. The apparent lack of interest in this compound as a designer drug may result from its poor solubility in water.

\section{Materials and methods}

Deuterated dimethyl sulfoxide (DMSO- $d_{6}$ ), deuterated chloroform $\left(\mathrm{CDCl}_{3}\right)$ and other chemicals were purchased from Sigma-Aldrich (Poznań, Poland). Melting points were uncorrected.

The nuclear magnetic resonance (NMR) spectra were recorded using an UltraShield $400 \mathrm{MHz}$ apparatus (Bruker, Bremen, Germany) with $\mathrm{CDCl}_{3}$ or DMSO- $d_{6}$ as solvent. The peaks were referenced to the residual chloroform $\left(\mathrm{CHCl}_{3}\right.$; 7.28 and $77.04 \mathrm{ppm}$ ) and dimethyl sulfoxide (DMSO; 2.49 and $39.5 \mathrm{ppm}$ ) resonances in ${ }^{1} \mathrm{H}$ and ${ }^{13} \mathrm{C}$ NMR. The NMR data are presented in the Supplementary Material.

The infrared (IR) spectra of each compound were obtained using a Nicolet iS50 Fourier transform infrared (FTIR) spectrometer (Thermo Scientific, Warsaw, Poland) and the attenuated total reflectance technique. Raman measurements were performed using a Thermo Scientific ${ }^{\mathrm{TM}}$ DXR ${ }^{\text {TM}} 2$ xi Raman imaging microscope equipped with a 780-nm laser (Thermo Scientific).

Gas chromatography-mass spectrometry (GC-MS) analyses were performed using a Thermo Trace GC Ultra chromatograph coupled to a mass spectrometer (Thermo DSQ; Thermo Scientific). The injector was maintained at $260{ }^{\circ} \mathrm{C}$. A $1-\mu \mathrm{L}$ aliquot of the sample was injected in the splitless mode. Separation of sample components was conducted using the $\mathrm{Rxi}^{\circledR}{ }^{\circledR}-5 \mathrm{Sil} \mathrm{MS}$ column (30 m length, $0.25 \mathrm{~mm}$ inner diameter, $0.25 \mu \mathrm{m}$ film thickness; Restek, Bellefonte, PA, USA). Helium was used as carrier gas at a flow rate of $1.2 \mathrm{~mL} / \mathrm{min}$. The mass detector was set to positive electron ionization (EI) mode, with electron energy of $70 \mathrm{eV}$. The mass detector was operated in a full-scan mode in the 40-450-amu range.

The single-crystal X-ray experiments were performed at $100 \mathrm{~K}$ for compounds $\mathbf{1}$ and $\mathbf{3}$, and at $293 \mathrm{~K}$ for compound 2. The data were collected using a SuperNova kappa diffractometer with an Atlas charge-coupled device detector (Rigaku Europe, Chalgrove, UK). For the integration of the collected data, CrysAlis ${ }^{\text {Pro }}$ software (version 1.171.38.41q, 2015; Rigaku Europe) was used. The solving and refining procedures were similar for all compounds. The structures were solved using direct methods with SHELXS97 software, and the solutions were refined using SHELXL-2014/7 software [16]. CCDC 1816306 for 1, CCDC1819495 for 2, and CCDC 1816307 for $\mathbf{3}$ are included in the supplementary crystallographic data as part of this paper. These data can be obtained free of charge from the Cambridge Crystallographic Data Centre ( www.ccdc.cam.ac.uk/data_request/ cif).

\section{Results and discussion}

Compounds 1-3 required for X-ray analysis were obtained from $\mathrm{L}-(-)$-ephedrine hydrochloride at $5 \mathrm{mmol}$ reaction scale, according to the scheme shown in Fig. 2. Compound 1 was synthesized from ephedrine according to the procedure described in [10] and compared with the materials seized by drug enforcement agencies on the illicit drug market. Compound $\mathbf{2}$ was obtained according to the procedure reported in [17]. It occurs as a mixture of two rotamers (1.1:1 ratio), as described previously (a 2.8:1 rotamer mixture) [18]. Oxidation of compound $\mathbf{2}$ was carried out in analogy with obtaining compound 1. Particular intermediate products were obtained with moderate yield (40\%). Reaction efficiencies were not optimized. Physicochemical data pertaining to compounds $\mathbf{1}$ and $\mathbf{2}$ were identical with those reported (although compound $\mathbf{2}$ was obtained in [18] as a colorless liquid). Compound $\mathbf{3}$ was obtained in [17] as a colorless liquid (no information was given concerning isomer type). We obtained all three compounds as solids, and their structures were corroborated by the crystallographic study. 
Fig. 2 Preparation route for compounds 1-3 from L-(-)ephedrine hydrochloride

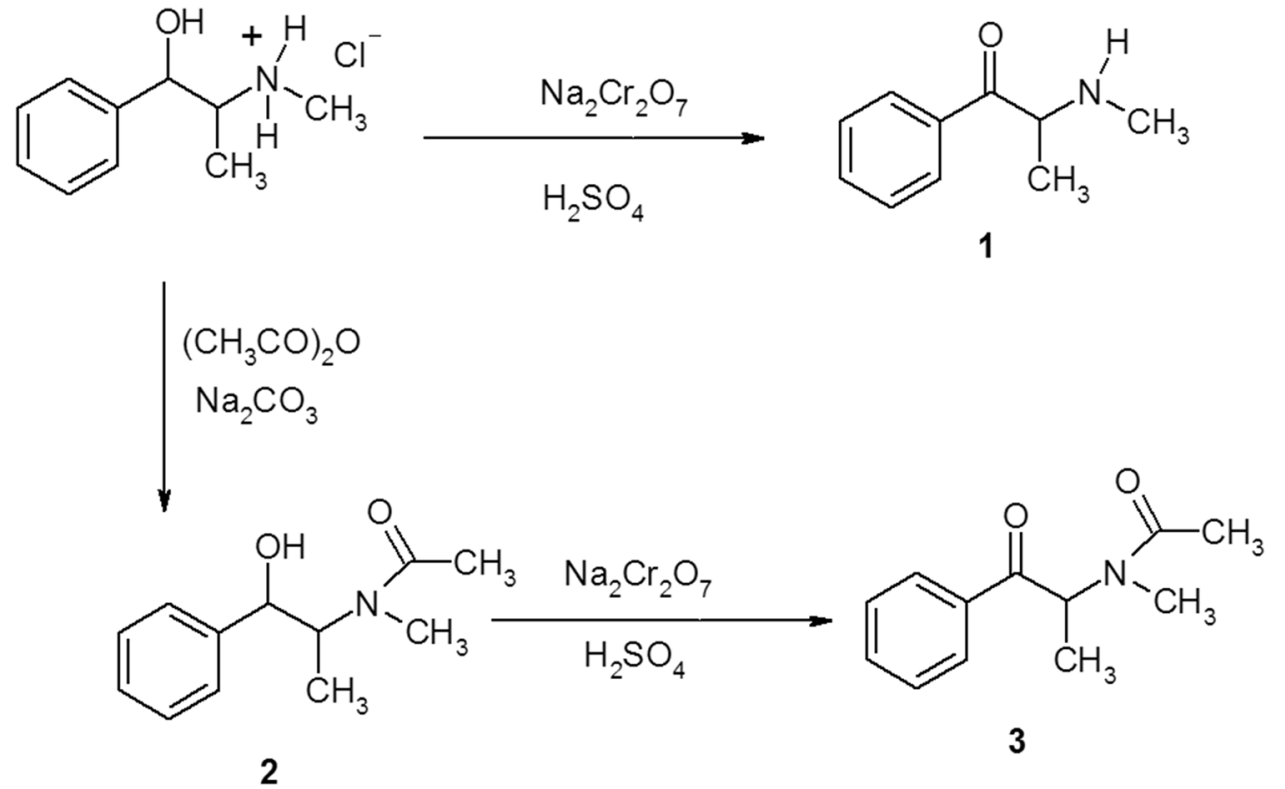

\section{GC-MS spectra}

Chromatography analyses of ephedrone have been frequently reported $[19,20]$. The GC-MS spectra of this generated compound in our study were compared with those of the other two. These data can be helpful in analyzing other possible ephedrine derivatives. Signals from molecular ions of all three compounds were present at low intensities, at $5-15 \%$. Iminium ions $(\mathrm{m} / \mathrm{z}=58)$ were observed to be dominant for all compounds. In the case of ephedrone (1), it is formed in a single process of bond cleavage between carbon atoms $\alpha$ and $\beta$ in the side chain. In the case of compounds $\mathbf{2}$ and $\mathbf{3}$, beside the cleavage just described above, there was another cleavage present (that of an acetyl group from the nitrogen atom). The mass spectral fragmentation patterns of all compounds are presented in the Supplementary Material (Figs. S1 and S2).

\section{NMR spectra}

The structure of compound $\mathbf{1}$ has been corroborated by ${ }^{1} \mathrm{H}$ NMR and ${ }^{13} \mathrm{C}$ NMR spectra. ${ }^{1} \mathrm{H}$ NMR data for this compound were published previously but for another solvent system (DMSO- $d_{6}+\mathrm{D}_{2} \mathrm{O}$ ) [11]. For this particular solvent mixture, the authors observed a multiplet of benzene ring protons. When using pure DMSO- $d_{6}$ as a solvent, particular protons were distinguished as a doublet at $\delta=8.04 \mathrm{ppm}$ $(J=8 \mathrm{~Hz})$ from ortho protons, a triplet at $\delta=7.76 \mathrm{ppm}$ $(J=8 \mathrm{~Hz})$ from para protons and a triplet at $\delta=7.62 \mathrm{ppm}$ $(J=8 \mathrm{~Hz})$ from meta protons in the benzene ring (see Supplementary Material). A similar spectrum was also reported in [9], although it is difficult to say whether it represented pure ephedrone or ephedrone hydrochloride; the lack of any signal from amine proton and good solubility in chloroform would suggest the presence of the former species. Another paper [21] reported two spectra identical to ours, which also had no NH proton signals. These spectra were obtained using $\mathrm{CDCl}_{3}$ and $\mathrm{CD}_{3} \mathrm{OD}$. In our spectra, a broad signal of amine protons at $\delta \sim 9.25 \mathrm{ppm}$ was clearly distinguishable. ${ }^{13} \mathrm{C}$ NMR spectra were given in [9] and [21]. Concerning [9], the authors provided signal shift values for all carbon atoms in the molecule, including that for carbonyl carbon, which in itself was proof of obtaining ephedrone from ephedrine. In [21], the signal from this carbon atom was clearly seen at $\delta=195.22 \mathrm{ppm}$. In our study, this shift was $\delta=196.8 \mathrm{ppm}$. The remaining signals are presented in the Supplementary Material.

Compound 2 occurred as two rotamers at an almost equimolar ratio (1.1:1 value derived from NMR spectrum). Particular protons and carbons from both rotamers displayed various signal shifts in ${ }^{1} \mathrm{H}$ NMR and ${ }^{13} \mathrm{C}$ NMR spectra, respectively. Aromatic protons in compound $\mathbf{2}$ occurred as a complex multiplet. Proton signals from the $\mathrm{OH}$ groups of both rotamers occurred adjacent to one another; the signals were stretched out, and their position was sample concentration-dependent, as well as dependent on the presence of other molecules (e.g., water) in the solvent. The proton signals occurred at 5.43 and $5.65 \mathrm{ppm}$ (see Supplementary Material). All the remaining protons occurred as two distinct signals, the ascription of which to a particular rotamer type can be determined by two-dimensional correlation spectroscopy. In ${ }^{13} \mathrm{C}$ NMR spectra, the signals of all carbon atoms from rotamer molecules occurred as double peaks. Such spectra contained only one (double) signal from the carbonyl group at $\delta=170.0 \mathrm{ppm}$ (169.7 ppm for the rotamer) in the acetyl moiety. Likewise, the signal from carbon in $\mathrm{C}-\mathrm{OH}$ 
occurred only at $\delta=75.1 \mathrm{ppm}$ (74.8 ppm for the rotamer), which showed that no acylation of the hydroxyl group took place in compound 2 ; the possibility of obtaining an acetyl derivative was reported in $[22,23]$. The remaining signals are presented in the Supplementary Material. The first ${ }^{1} \mathrm{H}$ NMR spectra of compound 2 published in [17] and [24] did not show the presence of double signals for particular proton groups; it was suggested that this occurs only in the case of the compound's enantiomer mixture. A subsequent report [25] confirmed the occurrence of rotamers in pure enantiomers of compound 2 and doubling of ${ }^{1} \mathrm{H}$ NMR spectrum signals.

Compound $\mathbf{2}$ in solution can theoretically occur in three conformations, which are shown in Fig. S3 (Supplementary Material). As is obvious from crystallographic studies described below, the presence of conformer 2a in the crystal has been confirmed. Based on this knowledge and on ${ }^{1} \mathrm{H}$ NMR spectral data, the other conformer present in solutions of this compound was $\mathbf{2 c}$. This is in accordance with earlier conformational [26] and spectroscopic [27] analyses of ephedrine.

Compound 3 was characterized based on well-separated peaks from aromatic protons: a doublet at $\delta=7.96 \mathrm{ppm}$ $(J=8 \mathrm{~Hz})$ from ortho protons, a triplet at $\delta=7.55 \mathrm{ppm}$ $(J=8 \mathrm{~Hz})$ from para proton, and a triplet at $\delta=7.44 \mathrm{ppm}$ $(J=8 \mathrm{~Hz})$ from meta protons of the benzene ring. The lack of signal from amine group protons confirmed its acylation. The peak of $\mathrm{C}-\mathrm{H}$ proton was strongly shifted $(\delta=6.15 \mathrm{ppm})$. The ${ }^{13} \mathrm{C}$ NMR spectrum was characterized by the presence of signals from two carbonyl carbon atoms: one presented in an amide group ( $\delta=170.4 \mathrm{ppm})$ and the other in $\mathrm{Ar}-\mathrm{CO}$ $(\delta=199.3 \mathrm{ppm})$. The remaining peaks occurred in the expected positions.

\section{IR and Raman spectra}

IR and Raman spectra can be useful for characterizing the synthesis of designer drugs. Spectral analysis of mixtures can reveal much information about particular stages of synthesis. In the case of ephedrone and its derivatives synthesized from ephedrine, pseudoephedrine or their derivatives (e.g., acetylated derivatives), characteristic vibrations of ketone or hydroxyl groups allowed the assessment of a putative route of synthesis for an examined compound. FTIR and Raman FT spectra of compound $\mathbf{1}$ were reported in [21]. These spectra are identical with those (denoted as Figs. S4 and S7) generated in our study, and presented together with spectra of compounds 2 (Figs. S5 and S8) and 3 (Figs. S6 and S9), respectively (see Supplementary Material).

Vibrations of the carbonyl group from a propionic fragment occurred in similar positions in the FTIR spectra of compounds 1 and 3 (1687 and $1688 \mathrm{~cm}^{-1}$, respectively). Compound $\mathbf{3}$ had yet another carbonyl group vibrational band at $1629 \mathrm{~cm}^{-1}$, originating from this compound's acetyl moiety. The spectrum of compound 2 featured one strong vibrational $\mathrm{CO}$ band from an acetyl fragment at $1602 \mathrm{~cm}^{-1}$, as well as a very strong band at $3275 \mathrm{~cm}^{-1}$, characteristic of vibrations of $\mathrm{OH}$.

In the Raman spectra of compounds $\mathbf{1}-\mathbf{3}$, the most characteristic were $\mathrm{C}=\mathrm{O}$ and aromatic ring vibrations. The $\mathrm{C}=\mathrm{O}$ absorptions appeared at $1686 \mathrm{~cm}^{-1}$ for $\mathbf{1}$, at $1603 \mathrm{~cm}^{-1}$ for 2 , and at $1686 \mathrm{~cm}^{-1}$ and $1628 \mathrm{~cm}^{-1}$ for 3 . The aromatic ring vibrations appeared at 1597,1580 , and $1596 \mathrm{~cm}^{-1}$ for compounds $\mathbf{1}-\mathbf{3}$, respectively.

\section{X-ray analysis}

The salt $\mathbf{1}$ was crystallized from DMSO solution as colorless plate-like crystals. Compound $\mathbf{2}$ was crystallized from water, also as colorless plate-like crystals. Compound $\mathbf{3}$ was crystallized from chloroform solution as colorless needle-shaped crystals. The crystal structures of compound $\mathbf{1}$ are shown in Fig. 3 (crystal structures for $\mathbf{2}$ and $\mathbf{3}$ are shown in Figs. S10 and S11, whereas crystal packing is shown in Figs. S14 and $\mathrm{S} 15$, respectively). Crystal data and structure refinement for compounds 1-3 are presented in Table 1 .

Both cathinones $\mathbf{1}$ and $\mathbf{3}$ occurred as expected $S$-isomers, which was in accordance with the mechanism of their formation from L-(-)-ephedrine. Both molecules crystallized in orthorhombic space groups. In the crystallographic structure of compound $\mathbf{1}$, an important role was assigned to the $\mathrm{N}-\mathrm{H} \cdots \mathrm{Cl}^{-}$hydrogen bonds. The $\mathrm{N}-\mathrm{H}$ donors (from $\mathrm{R}_{1} \mathrm{R}_{2} \mathrm{NH}_{2}{ }^{+}$groups) donated the hydrogen bonds to chloride anions separated from one another by a distance of 2.166 to $2.280 \AA$, with $\mathrm{N}-\mathrm{H}^{\cdots} \cdots \mathrm{Cl}^{-}$angles from $147.89^{\circ}$ to $157.32^{\circ}$. The separation of $\mathrm{N}^{\prime \cdots} \mathrm{Cl}^{-}$was between 3.017 and 3.089 $\AA$. Distances and angles listed above were similar to those reported in [28]. Analysis of crystal packing in compound $\mathbf{1}$ revealed much empty space between molecules, especially considering the packing along the $b$ axis of the elementary cell (Fig. 4). The schemes of crystal packing along other axes are presented in Figs. S12 and S13. Crystal packing for compounds $\mathbf{2}$ and $\mathbf{3}$ is shown only along the $b$ axis in Figs. S14 and S15, respectively.

$\mathrm{N}$-Acetylephedrine (2) crystal which we managed to obtain from aqueous solution contained only one kind of conformer in the elementary cell. No other conformer was found to be present in solution, and this was corroborated by NMR spectra, both in this study and in $[24,25]$. The hydroxyl group in compound 2 played a fundamental role in the arrangement of particular molecular fragments relative to one another, which is likely of importance to the packing of molecules in the elementary cell. The presence of an intramolecular $\mathrm{C} 9-\mathrm{H} \cdots \mathrm{O} 1$ hydrogen bond of $2.503 \AA$ could be noted, although the $\mathrm{D}-\mathrm{H} \cdots \mathrm{A}$ angle was only $123.39^{\circ}$, along with an intermolecular hydrogen bond between the $\mathrm{OH}$ 
Fig. $3(S)$-Enantiomer molecule of compound 1 in the crystal. Ellipsoids for non-H atoms correspond to $50 \%$ probability levels
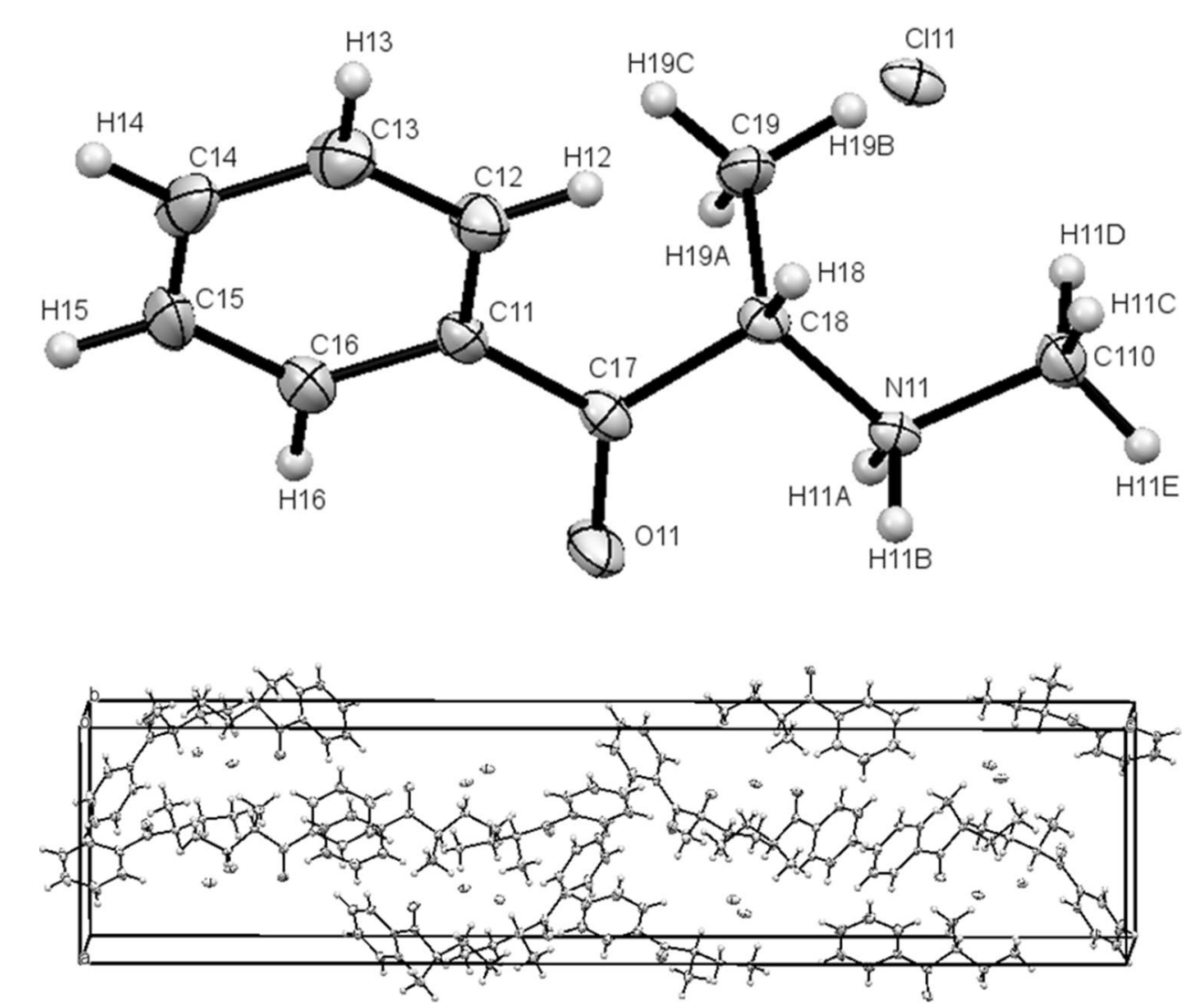

Fig. 4 Packing diagram for $\mathbf{1}$ : view along the $b$ axis group of one molecule and the oxygen atom from an adjacent acetyl group (length $1.989 \AA$, angle D-H $\cdots A$ A $171.15^{\circ}$ ). The positioning of the phenyl ring with respect to the molecule's skeleton may be stabilized by a weak hydrogen bond $\mathrm{C}_{\mathrm{Ar}}-\mathrm{H} \cdots \mathrm{OH}$ (length $2.625 \AA$, angle $\mathrm{D}-\mathrm{H} \cdots \mathrm{A}-140.56^{\circ}$ ), as well as with a $\mathrm{C}-\mathrm{H} \cdots \mathrm{Ar}_{\text {centr }}$ bond (length $2.684 \AA$, angle D-H $\cdots$ A $-143.88^{\circ}$ ). The characterized crystal of compound 2 featured conformer 2a (Fig. S17). No other stable conformers could be confirmed in the examined crystal.

Compound 2's conformation was "forced" by the occurrence of weak hydrogen bonds between oxygen atoms (O1 and $\mathrm{O} 2$ ) and hydrogen atoms from methyl groups at the C9 nitrogen and C12 carbon. All distances which could be determined between hydrogen atoms and their acceptors (oxygen atoms) were shorter (2.246, 2.503 and 2.551 A) than the sum of the van der Waals radii for these elements (2.72 ̊) (Fig. S18).

The crystallographic structure of compound $\mathbf{3}$ differed significantly from that of compound 2 . Due to the lack of an ionized fragment in the molecule, which would facilitate its solubility in water, it also lacked strong intermolecular hydrogen bonds. The acetamide fragment was planar with an almost ideal $\mathrm{Nsp}^{2}$ atom. This fragment existed in the mesomeric form characteristic for peptide bonds, in which a single bond occurs between $\mathrm{C}$ and $\mathrm{O}$ atoms and a double bond between $\mathrm{C}$ and $\mathrm{N}$ atoms.

Weak hydrogen bonds occurred between oxygen atoms from carbonyl groups (both at C7 atom and in acetyl substituent; Fig. S16 in Supplementary Material) and protons from adjacent molecules. One can also find a few weak intramolecular hydrogen bonds which stabilize a characteristic bend of the benzene ring with respect to the plane of the amide fragment (see Supplementary Material).

\section{Conclusions}

Ephedrone, which is easily made at home from legally available drugs, may be among the most frequently abused designer narcotics. Methods of obtaining this harmful compound are available on the web. Despite straightforward synthesis, the end product is contaminated with manganese ions, believed to be involved in the development of druginduced parkinsonism. Spectroscopic and crystallographic data concerning ephedrone and its acetylated derivatives could be helpful in assessing evidence in criminal proceedings. The NMR spectra of compound 2 suggest the existence of two stable conformers of this compound in solution, although the crystallographic structure determined during 
Table 1 Crystal data, data collection, and structure refinement for compounds $\mathbf{1}-\mathbf{3}$

\begin{tabular}{|c|c|c|c|}
\hline & 1 & 2 & 3 \\
\hline Chemical formula & $\mathrm{C}_{10} \mathrm{H}_{14} \mathrm{~N}_{1} \mathrm{O}_{1} \mathrm{Cl}_{1}$ & $\mathrm{C}_{12} \mathrm{H}_{17} \mathrm{~N}_{1} \mathrm{O}_{2}$ & $\mathrm{C}_{12} \mathrm{H}_{15} \mathrm{~N}_{1} \mathrm{O}_{2}$ \\
\hline Molecular weight & 199.67 & 207.26 & 205.25 \\
\hline Temperature (K) & 100 & 293 & 100 \\
\hline Wavelength $(\AA)$ & 0.71073 & 0.71073 & 0.71073 \\
\hline Crystal system & Orthorhombic & Tetragonal & Orthorhombic \\
\hline Space group & $P 2_{1} 2_{1} 2_{1}$ & $P 4_{3} 2_{1} 2_{1}$ & $P 2_{1} 2_{1} 2_{1}$ \\
\hline \multicolumn{4}{|l|}{ Unit cell dimensions } \\
\hline$a(\AA)$ & $10.0074(2)$ & $7.1249(1)$ & $9.0265(1)$ \\
\hline$b(\AA)$ & 10.1833(1) & $7.1249(1)$ & $10.0699(2)$ \\
\hline$c(\AA)$ & $44.3015(8)$ & $44.1371(15)$ & $12.3493(2)$ \\
\hline$\beta\left(^{\circ}\right)$ & 90 & 90 & 90 \\
\hline$V\left(\AA^{3}\right)$ & $4514.69(13)$ & $2240.58(10)$ & $1122.50(3)$ \\
\hline$D_{\text {calc }}\left(\mathrm{mg} \mathrm{m}^{-3}\right)$ & 1.175 & 1.229 & 1.215 \\
\hline$Z$ & 16 & 8 & 4 \\
\hline Absorption coefficient $\left(\mathrm{mm}^{-1}\right)$ & 0.303 & 0.083 & 0.083 \\
\hline$F(000)$ & 1696 & 896 & 440 \\
\hline Crystal size $\left(\mathrm{mm}^{3}\right)$ & $0.12 \times 0.10 \times 0.07$ & $0.12 \times 0.10 \times 0.10$ & $0.09 \times 0.08 \times 0.02$ \\
\hline Theta range for data collection $\left({ }^{\circ}\right)$ & $2.891-26.373$ & $3.004-36.342$ & $3.031-26.368$ \\
\hline \multirow[t]{3}{*}{ Index ranges } & $-12 \leq \mathrm{h} \leq 12$ & $-11 \leq \mathrm{h} \leq 11$ & $-10 \leq \mathrm{h} \leq 11$ \\
\hline & $-12 \leq \mathrm{k} \leq 12$ & $-11 \leq \mathrm{k} \leq 11$ & $-11 \leq \mathrm{k} \leq 12$ \\
\hline & $-55 \leq 1 \leq 55$ & $-67 \leq 1 \leq 70$ & $-15 \leq 1 \leq 15$ \\
\hline Reflections collected & 46577 & 41278 & 9410 \\
\hline Independent reflections & $9220\left[R_{(\mathrm{int})}=0.0346\right]$ & $5245\left[R_{(\mathrm{int})}=0.0893\right]$ & $2290\left[R_{\text {(int) }}=0.0186\right]$ \\
\hline Data/restraints/parameters & $9220 / 0 / 478$ & $5245 / 0 / 141$ & 2290/0/139 \\
\hline Goodness of fit on $F^{2}$ & 1.135 & 0.984 & 1.044 \\
\hline \multirow[t]{2}{*}{ Final $R$ indices $[I>2 \sigma(I)]$} & $R 1=0.0349$ & $R 1=0.0604$ & $R 1=0.0250$ \\
\hline & $w R 2=0.0748$ & $w R 2=0.1187$ & $w R 2=0.0671$ \\
\hline \multirow[t]{2}{*}{$R$ indices (all data) } & $R 1=0.0367$ & $R 1=0.1559$ & $R 1=0.0256$ \\
\hline & $w R 2=0.0756$ & $w R 2=0.1500$ & $w R 2=0.0676$ \\
\hline Largest diff. peak and hole $\left(\mathrm{e} \AA^{-3}\right)$ & 0.288 and -0.306 & 0.167 and -0.177 & 0.158 and -0.131 \\
\hline
\end{tabular}

analysis of aqueous solution-derived crystals demonstrated the presence of only one type of conformer.

\section{Compliance with ethical standards}

Conflict of interest The authors have no financial or other relations that could lead to a conflict of interest.

Ethical approval This article does not contain any studies with human participants or animals performed by any of the authors.

Open Access This article is distributed under the terms of the Creative Commons Attribution 4.0 International License (http://creativeco mmons.org/licenses/by/4.0/), which permits unrestricted use, distribution, and reproduction in any medium, provided you give appropriate credit to the original author(s) and the source, provide a link to the Creative Commons license, and indicate if changes were made.

\section{References}

1. Eberhard A (1915) Ueber das Ephedrin und verwandte Verbindungen. Arch Pharm 250:62-91

2. Hyde JF, Browning E, Adams R (1928) Synthetic homologs of d,l-ephedrine. J Am Chem Soc 50:2287-2292

3. Abdullah AFL, Chang KH, Jayaram SK, Sulaiman M (2014) A review on synthetic cathinone and its derivatives:prevalence and syntheses. Malays J Forensic Sci 5(2):46-52

4. Zuba D (2007) Medicines containing ephedrine and pseudoephedrine as a source of methcathinone. Probl Forensic Sci 71:323-333. http://www.forensicscience.pl/pfs/71_zuba.pdf

5. totse.com (2014) Methcathinone and ephedrone. https://totse ans.com/totse/en/drugs/speedy_drugs/cat.html. Accessed 14 Nov 2014

6. Erowid (2004) Methcathinone synthesis by oxidation of (pseudo) ephedrine with (di)chromate salts. https://erowid.org/archive/ rhodium/chemistry/catsynth.jones.html. Accessed Aug 2004

7. Sikk K, Haldre S, Aquilonius S-M, Taba P (2011) Manganeseinduced parkinsonism due to ephedrone abuse. Parkinsons Dis 2011:865319. https://www.hindawi.com/journals/pd/2011/865319 
8. de Bie RMA, Gladstone RM, Strafella AP, Ko J-H, Lang AE (2007) Manganese-induced parkinsonism associated with methcathinone (Ephedrone) abuse. Arch Neurol 64:886-889

9. Zhingel KY, Dovensky W, Crossman A, Allen A (1991) Ephedrone: 2-methylamino-1-phenylpropan-1-one (Jeff). J Forensic Sci 36:915-920

10. Kumar BNH, Murugesan V, Prakasam T, Srinivasan PS, Ramana DV (2009) Chiral $\alpha$-alkylation/arylation in 1-phenyl2-(1-pyrrolidynyl)-1-propanol through Grignard reactions. Tetrahedron Asymmetry 20:2773-2779

11. Findlay JWA, Warren JT, Hill JA, Welch RM (1981) Stereospecific radioimmunoassays for $d$-pseudoephedrine in human plasma and their application to bioequivalency studies. J Pharm Sci 70:624-631

12. Trzybiński D, Niedziałkowski P, Ossowski T, Trynda A, Sikorski A (2013) Single-crystal X-ray diffraction analysis of designer drugs: hydrochlorides of metaphedrone and pentedrone. Forensic Sci Int 232:e28-e32

13. Nycz JE, Paździorek T, Małecki G, Szala M (2016) Identification and derivatization of selected cathinones by spectroscopic studies. Forensic Sci Int 266:416-426

14. Nycz JE, Małecki G, Zawiązalec M, Paździorek T (2011) X-ray structures and computational studies of several cathinones. J Mol Struct 1002:10-18

15. Delori A, Maclure P, Bhardwaj RM, Johnston A, Florence AJ, Sutcliffe OB, Oswald IDH (2014) Drug solid solution-a method for tuning phase transformations. CrystEngComm 16:5827-5831

16. Sheldrick GM (2015) Crystal structure refinement with SHELXL. Acta Crystallogr C71:3-8

17. Zhestkov VP, Voronin VG, Portnov YN (1983) Reaction of 1-(p-nitrophenyl)-2-acetylamino-1,3-propanediol with sodium hypochlorite. Pharm Chem J 17:657-660

18. Bogdan AR, Davies NL, James K (2011) Comparison of diffusion coefficients for matched pairs of macrocyclic and linear molecules over a drug-like molecular weight range. Org Biomol Chem 9:7727-7733

19. DeRuiter J, Hayes L, Valaer A, Clark CR, Noggle FT (1994) Methcathinone and designer analogues: synthesis, stereochemical analysis, and analytical properties. J Chromatogr Sci 32:552-564

20. Power JD, McDermott SD, Talbot B, O'Brien JE, Kavanagh $P$ (2012) The analysis of amphetamine-like cathinone derivatives using positive electrospray ionization with in-source collision-induced dissociation. Rapid Commun Mass Spectrom 26:2601-2611

21. SWG DRUG (2005) Methcathinone. http://www.swgdrug.org/ Monographs/METHCATHINONE.pdf. Accessed 11 July 2005

22. Mitchell W (1940) The acetylation of $d$ - $\psi$-ephedrine and $l$-ephedrine. J Chem Soc 1153-1155

23. Welsh L (1947) The constitution of acetylephedrine and acetyl$\psi$-ephedrine. J Am Chem Soc 69:128-136

24. Carroll FI, Blackwell JT (1974) Optical isomers of aryl-2-piperidylmethanol antimalarial agents. Preparation, optical purity, and absolute stereochemistry. J Med Chem 17:210-219

25. Köhl M, Spreitzer H, Fleischhacker W (1992) Reaktionen von (-)-Ephedrin bzw. (+)-Norpseudoephedrin und Derivaten mit $N, N$-Dimethylacetamid-dimethylacetal und $N, N$-Dimethylformamid-dimethylacetal. Monatsh Chem 123:911-918

26. Gourlay MD, Kendrick J, Leusen FJJ (2007) Conformational analysis of ephedrine using molecular mechanical, semi-empirical and $a b$ initio quantum mechanical methods. J Mol Struct 809:11-20

27. Portoghese PS (1967) Stereochemical studies on medicinal agents. IV. Conformational analysis of ephedrine isomers and related compounds. J Med Chem 10:1057-1063

28. Steiner T (1998) Hydrogen-bond distances to halide ions in organic and organometallic crystal structures: up-to-date database study. Acta Crystallogr B54:456-463 